\title{
A Lean Proposal: Development of Value Stream Mapping for L'Oreal's Artwork Process
}

\author{
Sid Ghosh (The Business School, Bournemouth University, Poole, UK) \\ Kaitlin Lever (L'Oreal Ltd, London, UK)
}

\begin{abstract}
Purpose: This research develops value stream mapping (VSM) for L'Oreal's artwork process, to eliminate waste, reduce lead-time and identify stages that can be automated, which makes the process less prone to human error and more responsive to fulfilling business-to-business customer requirements. Additionally, amendments frequently occur slowing down the artwork process. In this context VSM is applied to L'Oreal's artwork process to reduce lead-time, human error and missed deadlines.
\end{abstract}

Design/ Methodology/ Approach: This study uses data from L'Oreal's artwork tracker from 2018-2019, which is manually tracked by the launch team. The service level agreement and task time data has been collected from 12 employees representing the launch, factory and marketing teams working on the artwork process. Qualitative feedback was also obtained from 9 employees to validate the VSM for L'Oreal's artwork process.

Findings: VSM identified stages that can be streamlined and automated in L'Oreal's artwork process, which makes the process more efficient and responsive to changing scope of the artworks. 50 percent of the stages have been eliminated from the manual artwork process, resulting in a reduced lead-time of 10.5 days and a reduction of 28 percent time spent on the process. This allows the artwork process to be more agile to the requirements of business-to-business customers. Moreover, the proposed VSM shows a $73 \%$ increase in value added time for a renovation and a $75 \%$ increase in value added time for new product developments (NPD).

Originality/ Value: VSM has been specifically designed, developed and analyzed for L'Oreal's artwork process, in order to make the process more efficient and responsive to business-to-business customers requirements.

Keywords: VSM, lean tools, artwork-process, L'Oreal, automation 


\section{Introduction}

Reducing waste and eliminating non-value added work from processes has become increasingly important in organizations, to succeed in a competitive business environment. Value stream mapping (VSM) is a lean tool that identifies non-value added work in a process. If non-value added work is eliminated, processes will become more efficient and customer focused, this enables organizations to be more responsive in fulfilling business-to-business customers requirements effectively. VSM also enables processes to be more agile as valuable time is freed up to respond to changes, making the process more flexible. VSM has been used within many functions in a business, such as operations and supply chain management, however, its application within marketing has not been extensively explored. This paper attempts to fill this gap by applying VSM to L'Oreal's artwork process (AP) to meet the changing requirements of business-tobusiness customers.

The artwork process (AP) at L'Oreal is used to create labels for products in the consumer products division. These are created in 12 countries across Europe for language specific artworks. This study is going to focus on the artworks created in the U.K. However, it is anticipated that this research should be applied and integrated across the countries in Europe. Artworks are shared with functions in Launch, marketing, the suppliers, legal and scientific, TAG and production in the format of PDF and editable files. TAG is an external company that creates the editable files. There are currently 12 stages in the process, which are all communicated via email. As a result, there is insurmountable room for human error, work duplication and no visibility on the status of the artworks, which causes increased costs, missed deadlines and delays in production. A new automated process 
that allows each function to see the status of artworks and the corresponding deadlines would help to minimize deadlines being missed. VSM has the capabilities to identify specific non-value added work in L'Oreal's AP, if eliminated this would help to reduce the lead-times and the number of missed deadlines.

\section{Literature review}

The concept of lean was first introduced in 1978, in Japan by Ohno and Shingo, who emphasized the maximization of resources and elimination of waste (Al Hroub et al., 2019; Vinodh et al., 2013). Additionally, James Womack led the benchmark study of lean manufacturing on the Toyota Production System in the 1980s (Solaimani et al., 2019). As a result, he produced a best set of practices, which was termed as Lean Management (cited in Solaimani et al., 2019). These practices were developed to improve quality and productivity, they are predicated on two philosophies; reduction of waste and respect for people (Jacobs and Chase, 2017). Today lean techniques and manufacturing are being implemented globally in a variety of industries and sectors (Kale and Parikh, 2019). Al Hroub (2019) defines lean management as: "the techniques and tools utilized to eliminate and reduce the waste in a process while improving the productivity and effectiveness in the workflow". In summary, this literature review aims to evaluate the suitability of lean tools, specifically value stream mapping (VSM) as a tool that will be used to identify where improvements should be made in L'Oreal's AP. Furthermore, agile theory will be discussed in order to find the optimal AP that is efficient from the application of lean concepts yet responsive to the needs of the business-to-business customers. 


\subsection{Lean tools and its application on L'Oreal's AP}

The concept of lean manufacturing has evolved over time and there has been an increased focus on the importance of adding value (Jacobs and Chase, 2017). "Lean is about making value flow at every step" (Camgoz-Akdag et al., 2017). Therefore, in order to receive the best possible outputs, there needs to be a balance between efficiency and effectiveness (Gharfalkar et al., 2017). Whilst, efficiency aims to maximize resources, effectiveness refers to value-added (Solaimani et al., 2019; Gharfalkar et al., 2017). Both are vital in order to deliver successful outputs (Jones et al., 1997). In the context of L'Oreal's AP, the objective is to create artworks devoid of mistakes and errors, following the most efficient path through the application of lean tools, such as VSM. Inputs from other functions, such as wasted time will be significantly reduced, resulting in a more efficient process. Mapping the current process by using a lean tool such as VSM has the capability to identify wastes (Hines and Rich, 1997). Waste is defined as any activities that do not add value from the customer or client's perspective (Al Hroub, 2019). Schroder and Goldstein (2018) identify seven forms of waste: Overproduction, waiting time, unnecessary transportation, excess processing, too much inventory, unnecessary motion, and defects. For L'Oreal's AP excess processing, waiting time and defects contribute to wastes that occur in this process. If organizations want to successfully reduce waste and streamline their processes, management needs to be better educated on lean tools such as VSM, otherwise, senior levels of management are less likely to buy-in to the idea of lean practices (Hines et al., 1998). Furthermore, Hines et al. (1998) also outlines that there is a lack of understanding in management of what becoming lean means and how this is accomplished. Additionally, it is recommended that on the job training be given to employees to outline what the concept of lean means. (Kumar et al., 2018; Serrano-Lasa et al., 2008) 


\subsection{Value Stream Mapping and its application to L'Oreal's AP}

A Lean tool frequently used in process improvement is value-stream mapping (VSM) (Dadshneiad and Valmohammadi, 2018). "Value stream mapping is a graphical way to analyze where value is or is not being added as material flows through a process" (Jacobs and Chase, 2017). VSM looks at the current process and develops a 'current state map', which visually demonstrates how a process works, through identifying data and communication flows (Dinis-Carvalho et al., 2019; Kale and Parikh, 2019). The way information flows in this map is what differentiates VSM from other tools (Kale and Parikh, 2019). The VSM splits the activities into three sections; value-adding, non-value adding and necessary non-value-adding. The goal is to eliminate all of the non-value adding activities and to optimize the value adding activities (Kale and Parikh, 2019; Jacobs and Chase, 2017; Hines and Rich, 1997). According Singh et al. (2019) eliminating non-value activities helps organizations to provide quality that satisfies the demands of business-tobusiness customers.

VSM has not been explored and applied to a marketing process such as L'Oreal's AP, however, Solaimani et al. (2019) conclude that VSM has many strengths, that can be applied to any business activity and can be expanded upstream or downstream. Furthermore, this tool also highlights process inefficiencies, transactional and communication mismatches, pinpoints where improvements should be made and where waste will be eliminated (Solaimani et al., 2019; Singh et al., 2011). Hines (1998) states that the removal of waste in a supply chain setting is perhaps the most important task for modern-day logisticians. Furthermore, Rother and Shook (2003) strongly agree, however, they caution that before logisticians start trying to eliminate waste in the supply chain, they must map the entire value stream to gain the benefits of highlighting process inefficiencies 
and pinpointing where improvements should be made (Singh et al., 2011). Once this step has been taken, logisticians can quickly remove waste and will be surprised at the vast improvements that will be made in such a short amount of time (Rother and Shook, 2003). Russell and Taylor (2020) define waste as "Anything other than the minimum amount of equipment, effort, materials, parts, space, and time that are essential to add value to the product." The successful removal of waste is illustrated in the form of, reduced lead times, cost savings and the identification of areas for continual improvement (Jasti and Sharma, 2013). These areas will be identified in L'Oreal's AP using VSM. Therefore, the literature suggests that lean tools, specifically VSM, has the capabilities to improve any process and will therefore, be applied to a marketing process such as L'Oreal's AP (Solaimani et al., 2019).

Kaizen is a Japanese philosophy that focuses on continual improvement (Schroder and Goldstein, 2018) and is used in VSM to identify short-term projects that add value to the process and eliminate waste (Jacobs and Chase, 2017). These are added to the any generic VSM in order to show where improvements such as waste elimination and automation should be made (Schroder and Goldstein, 2018; Jacobs and Chase, 2017). "automation are technologies that make a global impact by optimizing manual and timeintensive processes using data analytics and robotics, thus making the task more efficient, effective and less time-consuming" (Foster et al., 2020, p.1). IBM, Mulesoft, and Microsoft are just a few of the companies that offer application-programming interfaces (API) (IBM, 2020; Mulesoft, 2019; Microsoft, 2020). API is a "software intermediary that allows two applications to talk to each other" (Mulesoft, 2019) and enables processes to be userfriendly (Zubkova and Tagirova, 2019). API should be applied to L'Oreal's AP by connecting the product code sheets to a bespoke system. 
Microsoft lists 1239 successful case studies of companies that have improved their processes by using API; companies included HP, ASOS, and Walgreens (Microsoft, 2020). Walgreens saw an improvement in its operations, lowered costs, modernized business processes and decision-making (Microsoft, 2020). At IBM (2020), "API Connect does it all, with the tools to agilely create, secure, manage and share APIs". In the context of L'Oreal's AP, an API system would enable the process to become leaner whilst also enabling agility in the process, improving both the efficiency and effectiveness of the AP. However, a drawback of API is that it is often be expensive (Zubkova and Tagirova, 2019). As a result, if management at L'Oreal is not familiar with this process, and the costs to implement a bespoke system using API are high, then the likelihood of L'Oreal implementing a new system could be significantly lower (Zubkova and Tagirova, 2019).

In contrast, a weakness of VSM is that it is difficult to use in complicated production systems with multiple routes, instead, it is suggested that VSM is most effective on a linear process (Singh et al., 2011). However, to address this issue Braglia et al. (2006) proposed a new framework, "improved value stream mapping". The process integrates other engineering tools and creates a current VSM, which breaks down the complicated production process and focuses on the critical path. After identification of the critical path, it was possible to identify where the improvements should be made (Braglia et al., 2006). As a result, the main value stream was improved, a new critical path was created and work in progress was decreased to a desirable level (Braglia et al., 2006). In addition, Braglia et al. (2006) and Singh et al. (2011) also highlighted that VSM is predominantly and paper-and-pencil based technique, therefore the accuracy level is limited. As a result, this tool may not be best suited to companies with a 'high variety-low volume type' 
production (Singh et al., 2011). However, L'Oreal's AP is a sequential multi-stage process where each stage is dependent on the other, therefore, will be effectively applied to L'Oreal's AP.

Furthermore, there is a vast amount of literature on lean tools such as VSM (Lugert et al., 2018; Matt, 2014). However, there is a lack of literature on VSM being applied to a marketing process. As a result, further development and research is needed in this area in order to maximize the usability and effectiveness of applying VSM to the AP. Despite the weaknesses of VSM (Singh et al., 2011; Braglia et al., 2006; Hines et al., 1998), the literature suggests that this process can be applied to marketing processes such as the AP (Solaimani et al., 2019), in order to identify where the process should be streamlined by eliminating non-value adding activities. This would increase the productivity and add value to the process (Kale and Parikh, 2019). Moreover, there have been several successful case studies that have used VSM (Saboo et al., 2014; Singh et al., 2011).

\subsection{Application of VSM in organizations}

Saboo et al. (2014) successfully implemented VSM in an Indian metal sheet production company. The company was facing problems with delivering products on time to its customers, due to a rise in demand. The firm agreed that lead-time, in-process inventory, bottlenecks, and cycle-time would benefit from being reduced. The VSM tools were implemented. As a result, the production lead-time was reduced from 49 days to 11.6 days. Furthermore, work-in-progress inventory was reduced from 28.15 days to 7.6 days. In Summary, the company has improved its quality, reduced operational costs and improved service levels for its customers. Similarly, VSM was used in the auto industry. As a result, production output per person was improved, work-in-progress was reduced 
and finished goods were reduced (Singh et al., 2011). Both of these examples highlight benefits that would significantly improve L'Oreal's AP. This will help to pinpoint process inefficiencies, highlight waste and indicate areas that should be continuously improved (Seth et al., 2007). Moreover, the AP is a linear process and therefore VSM will be successfully applied to the AP. However, the critical path should be taken into account and further research should be conducted to enable the AP to map the most efficient Proposed VSM that not only reduces waste but also adds value to the process. However, to map an effective process that adds value, process agility needs to be considered in conjunction with lean tools to create an optimal AP.

\subsection{Agile and its application to L'Oreal's AP}

Agile theories have a greater focus on effectiveness instead of efficiency (Kumar et al., 2019). According to Jacobs and Chase (2017), agile utilizes strategies aimed at being responsive and flexible to customer's needs. A process is agile if they have the ability to be responsive to the changing, diverse, and unpredictable demands of customers (Denning, 2016). When demand is stable and predictable a lean standardized process is preferred, whereas, agile is preferred when there is high customization in the products (Kumar et al., 2019). Suarez-Barraza et al. (2014) indicates that only organizations that devise agile and adaptable processes will be able to compete in today's environment. Agile is designed for flexibility and should be monitored continuously, and constantly improved and optimized (Rodriguez and Molina, 2018). The difference between agility and lean is that agility is less focused on the specific stages in a process and more oriented to the managerial and cultural context surrounding the process (Kumar et al., 2019; Denning, 2016). However, it is suggested that because VSM reduces such a vast amount of waste (Solaimani et al., 2019; Singh et al., 2011; Hines, 1998), it also enables 
processes to be more agile as valuable time is freed up to respond to changes, making the process more flexible. As L'Oreal's AP uses a predictable and repetitive process, a lean standardized process is preferred, however, the process should not become too lean to prohibit necessary amendments that need to be made (Denning, 2016). Amendments include changes in text, punctuation and any corrections that need to be made. These amendments currently have to go back through the many stages, which results in wasted time, often causing missed deadlines. Therefore, the concepts of agile should also be considered in addition to lean concept to find the optimal process that is not only efficient but also aims to fulfill the changing needs of business-to-business customers.

The literature suggests that lean theories such as VSM have the capabilities to significantly improve the AP and should be applied to any process including marketing processes (Solaimani et al., 2019; Singh et al., 2011; Hines, 1998). VSM will be created to map L'Oreal's current AP and has the capabilities to identify where non-value adding activities should be eliminated (Kale and Parikh, 2019; Solaimani et al., 2010). Secondly, a proposed VSM will be created showing the proposed data and information flows, by evaluating the current VSM, in order to eliminate non-value adding activities from the AP (Kale and Parikh, 2019). Furthermore, this will add value and enable the AP to be more productive as wasted time is freed up (Kale and Parikh, 2019). This freed time will also enable the process to be more responsive to changes and amendments, therefore creating a more agile AP (Kumar et al., 2019; Denning, 2016). When implementing an automated AP, non-value adding stages should be eliminated. Additionally, agile theory should be considered to create an optimal process (Denning, 2016). Furthermore, in order for VSM to be successful in an organization, senior levels of management need to be educated on lean concepts and its capabilities (Hines et al., 1998). 


\subsection{Research Method}

For this research project, data for the service level agreement (SLA), which is the time agreed for a task to be completed, and the task time was collected from 12 L'Oreal employees who worked in different functions and have specific knowledge of the artwork process within their function, as shown is figure 3. Furthermore, data ranging from 2018 to 2019 was collected from L'Oreal's artwork tracker, which is an excel document that the function launch use to manually track the dates and deadlines artworks are received and sent on to the factory, as shown in figure 4. Finally, data in the form of feedback, on the current VSM and Proposed VSM, was collected from nine employees, from different levels of seniority, to create a final proposed VSM. The data was obtained via email, and asked what advantages and disadvantages an automated system would have on their role. Moreover, employees were asked what changes should be made to the current VSM and the proposed VSM. Additionally, employees were asked what issues caused the most delays in artworks not being completed on time. Finally, the Launch manager was asked how much it costs to destroy products if mistakes have been made on an artwork. All data was obtained through email communication.

\subsection{Data Analysis, Findings and discussion}

L'Oreal's AP creates language specific artworks across Europe (Figure 1). Each brand corresponds with the nine different factories in Europe based on the products each factory produces (Figure 2). This study will discuss findings and data collected for products specifically in the UK market. 
12 L'Oreal employees were asked how many days they were given to complete a task and how long it took them to physically complete the task. The findings are illustrated and divided by each stage in the process in Figure 3.This is also divided by product renovations (A) and New Product Developments (B). A renovation is a small change to an already existing artwork. New product development is the creation of a new artwork that has not previously been used. Amendments are mistakes that occur on both renovations and NPD in the artwork process.

\section{"Bring in Figure 3"}

Furthermore, Figure 4 illustrates a sample of the data collected from the artwork tracker. The data is manually entered by launch. They act as an intermediary between the factory and marketing for the different brands. BAG is a French word that describes the process of adding the barcode to an artwork. The tracker tracks the dates launch receives a request for an artwork, the deadlines the artworks and BAG are due, and the dates these are sent back to the factory. The EAN is the number that is used on the barcode and cannot be sold if this number is incorrect. The EAN and material code is manually entered and is used to identify the specific artwork. Additionally, the artwork tracker has a section for comments, which is illustrated in figure 5 . The comments show some of the reasons artworks are pushed back and delayed for both renovations and NPD, highlighting the requirements for amendments.

"Bring in Figure 4 \& 5" 
Additionally, the launch manager was asked how much it costs to destroy products in the event that a mistake has been made on an artwork. Findings showed that added costs of $£ 145$ to destroy 1 pallet (2500 units) of general stock and $£ 240$ to destroy 1 pallet of flammable stock (2500 units) were incurred in addition to the unit cost of the product. In addition to these costs are the costs of internal transport and admin certificate charges, which costs approximately $£ 300$ for 5 pallets.

\subsection{Current VSM}

L'Oreal's AP has 12 stages these include; development, the factory, launch, marketing, TAG, the supplier and legal and scientific. TAG is a French word that describes the function that helps to create the files for artworks. The purpose of this process is to create the labels for products in the consumer products division. Furthermore, the AP is used for the following brands: Garnier Haircare, Garnier Skincare, Sun and Body, L'Oreal Paris Skincare.

Moreover, from the literature review, it was concluded that mapping the AP using VSM would highlight where there are high levels of waste, process inefficiencies and where improvements should be made in the process (Seth et al., 2007; Braglia et a., 2006; Hines et al., 1998). Furthermore, it was concluded that lean tools could be applied to any process (Solaimani et al., 2019; Hines et al., 1998). However, the process should not become too lean as to hinder a process from being flexible to changes. For L'Oreal's AP, the process needs to be able to respond effectively to changes that need to be made to artworks, such as scope changes, corrections, and amendments (Kumar et al., 2019). Therefore, a current VSM of L'Oreal's AP has been created and is shown in Table 1 and Table 2. The map has been split into two sections. Table 1 is the creation of artworks, stages 1-7. In 
this stage, marketing and TAG physically create the labels and send these to the supplier. Furthermore, Table 2 (stages 7-12) is where the supplier adds the barcode to the artwork (BAG), which is then sent back to marketing to check and approve and finally sent to be produced, where the labels are printed and ready to be sent to clients such as Boots and Superdrug.

The data in this map has been collected from 12 employees representing each function (Figure 3) at L'Oreal and is based on the service level agreement (SLA), which is the amount of time each function has agreed to complete their stage in the process. Moreover, this has been illustrated on the map as the longest SLA (Blue line) and the shortest SLA (Red line) and is calculated in minutes. Additionally, the number of days is shown in brackets, e.g., one working day is 420 minutes shown on the map as 420 (1), as illustrated in Tables 1-6. Furthermore, the data box (Table 1-6) contains the average of the longest SLA and shortest SLA as a percentage for value-added activities (VA) and non-value added activities (NVA). A renovation is a small change to an already existing artwork. New product development (NPD) is the creation of a new artwork that has not previously been used. Additionally, the VSM has been divided by product renovations (A) and NPD (B) in order to accurately evaluate how much value is being added. The envelope symbol (Table 1-6) identifies where the artwork or BAG is being transmitted as an attachment via email. Furthermore, the red ' $X$ ' and green tick (Table 1-6) highlights whether the artwork will move onto the next stage or needs to be pushed back to the specific stages (Grey arrow and corresponding number) for the amendments to take place. For example if an amendment is pushed back at stage 11 (Table 2) it will go back to stage 4 or 7 depending on the requirements. 


\subsection{Current VSM Findings}

The data collected identifies that it takes a minimum of 23 days and a maximum of 51 days to complete an artwork according to the SLA (stages $1-12$ ). However, only $2.48 \%$ of this time adds value for a renovation (A) and only $2.52 \%$ for a NPD (B), which is extremely low, as $97 \%$ (approximately) of the time is wasted (Figure 11). The highest VA is just under $12 \%$ in stage 4 (Table 1 , data box) of the process. There is significant room for improvement to create a more efficient and effective process, which will eliminate the wasted time in the current process (Kumar et al., 2019).

\section{"Bring in Tables 1 \& 2"}

\subsection{Current VSM compared with the Artwork Tracker}

The current VSM in Tables 1 and 2 highlights the SLA. This will be compared with the actual data collected from L'Oreal's artwork tracker, which enables authors to highlight possible process inefficiencies. L'Oreal's artwork tracker is tracked by launch and therefore, tracks stages 3 - 12 in the AP. Figure 6 illustrates the average time the factory allows marketing to complete the artwork and the time it takes for this artwork to be completed. Additionally, Figure 7 shows the time the factory allows for the entire process to be completed and how long it takes marketing to complete these.

\section{"Bring in Figure 6"}

According to the SLA, on average the factory has allowed sufficient time for renovations to be completed (6-14 days; stages 3-6, as shown in Table 1) however, for NPD sufficient time has not been allowed on average (13-24 days; stages 3-6, as shown in Table 1). 
However, it is not clear from the current AP whether the artworks are renovations or NPD, therefore, it is not possible to conclude whether the factory has allowed sufficient resources or marketing was late. An automated AP will remove this issue as data will be collected and monitored to ensure sufficient resources such as manpower and time are allocated, so that business-to-business customer requirements are effectively met (Kumar et al., 2019).

Additionally, 4 out of 5 brands missed the artworks deadlines when measured against the time the factory allowed (stages 3-6), ranges from 11 - 17 days, with sun and body performing the worst, taking 63 days on average to complete artwork and missing the deadlines on average by 48 days. Garnier Skincare performed better in relation to all the other brands, missing the average deadline by 8 days, despite being allocated the shortest time of 11 days to complete the artworks (Figure 6). As a result, it is therefore unclear whether the factory did not allow enough time for these artworks to be completed or whether the sole reason was due to marketing missing the deadlines due to miscommunication. When looking at the data closer Sun and Body's deadlines were impacted by human error; one artwork was 114 days late due to a miscommunication of information (Task deadline 27 August 2019 - submitted 21 ${ }^{\text {st }}$ December 2019). The marketing team believed these had already been completed, whereas the factory did not have these artworks and therefore production could not move forward. As a result, the marketing, factory and launch teams had to check through all of their emails to try and track them down, wasting time that should be spent on other work. They were unable to find the artworks needed, therefore, marketing had to recreate them, putting on hold other tasks that need to be completed, which resulted in duplicate work. Such long delays will have significant impacts on the clients and the customers if products are not produced in 
sufficient time. However, with an automated system data be automatically collected and differentiated to specifically identify where issues are frequently occurring. Furthermore, this will identify whether the SLA are sufficient for each function, or whether marketing require more resources (more time and man power) to meet the deadlines of businessto-business customer orders.

However, figure 8 illustrates stages 3-12, which shows the time allowed and the time it takes to complete all the tasks. 4 out of 5 brands still missed the deadlines to approve the BAG, with Sun and Body performing the worst missing the approval deadlines by an average of 40 days. Sun and Body were previously late by 48 days (stages 3-6). Furthermore, the reduction of 8 days from 48 days to 40 days means the stages between 7 - 12 have picked up the pace showing that there has been a reduction of 8 days. Additionally, these stages have had to prioritize these artworks ahead of other work, which will contribute to creating a bottleneck resulting in more missed deadlines.

\section{"Bring in Figure 7"}

Furthermore, for a renovation to be completed the SLA ranges from 16-43 days (stages 3-12, Table $1 \& 2$ ). 4 out of 5 brands were given more than 43 days to complete the artworks. L'Oreal Paris Haircare was given the lowest number of days (i.e. 38 days), however, they were the only brand to meet the BAG deadlines. In addition, for NPD the SLA ranges from 23-53 days. 3 out of 5 brands were given more than 53 days to complete NPD (stages 3-12, Table 1 \& 2), however, all of these brands still missed the deadlines. There are various reasons as to why these deadlines may be missed and the consequences they have, which is illustrated in Figure 8 in the form of a fishbone diagram. 


\subsection{Missed deadlines, amendments and human error: cause and effect analysis}

Figure 5 shows the issues that have been raised on the artwork tracker in the comments section. For example, comments included: "marketing requested 'Vegan Formula' to be added", "Artwork missing", and "Capital C needs to be amended". Each of these issues resulted in duplicate work and delays, as amendments needed to be made or artworks recreated, these are then pushed back to stage 4 or 7 (Table $1 \& 2$ ) depending on the changes that need to be incorporated in the artwork. These issues have been consolidated and illustrated in the form of a fishbone diagram (Figure 8).

\section{"Bring in Figure 8"}

Multiple causes result in missed deadlines and artworks needing to be amended. At L'Oreal graduates and interns are often responsible for the completion of artworks. These graduates switch roles every 6 months and interns every 12 months. As a result, work content and task requests are lost, due to email threads not available to the new graduate, which is especially difficult when trying to track down missing artworks. Furthermore, employee's positions change, each function needs to send email requests to the new previous contact, which has been relocated. Moreover, there is no standardized tracker that allows the new contact to see the status and progress of previous artworks, as the artwork tracker is not accessible to all functions. Similarly, the same difficulties occur when those responsible are on annual or sick leave as the work is stored in their email accounts.

Additionally, the lack of visibility and traceability will have knock on effects on urgent tasks. For example Garnier deodorants were raised on the tracker as "missing" once the 
deadline had passed. Production chased the factory for the Garnier deodorants, causing the factory to chase launch and marketing with little time to complete these. If artworks are delayed and do not meet their deadlines then production has to be postponed. As a result, orders are not fulfilled, which results in dissatisfied clients and customers. With an automated system many of these causes shown in Figure 8 should be avoided, as visibility on deadlines and the status of artworks would allow access at all times to all contacts and indicate when tasks have not been completed.

However, if mistakes are not identified before they go to production, then the product must be destroyed, which is a legal requirement. If 12,500 products need to be destroyed, an added cost of $£ 1025$ will be incurred for general stock and an added cost of $£ 1500$ for flammable stock, this is excluding the unit cost of the product. Legal requirements include the claims on a product; such as the expiry date e.g. 12 months or 18 months or a claim that a product has 'No Sulfate'. Furthermore, the correct EAN code (barcode) is a legal requirement, which should be automatically checked with a new system. For example, in January 2019, it was highlighted that the Garnier 7 Days Body Lotion was printed with the wrong EAN code on 100,000 units. It was estimated that it would cost approximately $£ 10,000$ to re-sticker the products. Additionally, the Superdrug order date was missed. This was due to human error; marketing simply selected the wrong code from the product code sheet. These mistakes are frequently made due to the manual process. Not only does this incur costs to L'Oreal, it also results in dissatisfied business-to-business customers, as the orders are not fulfilled to the agreed requirements. 


\subsection{Implications of amendments on lead-time}

Furthermore, delays occur due to amendments. The causes of these amendments is shown in Figure 8. The current VSM (Table 1 and 2) illustrates that amendments need to go back to stage 4 or stage 7 on the current VSM. These then go back through the stages simultaneously, which results in duplicate work, wasted time and longer lead times. Furthermore, if there are bottlenecks in the process, the pressure on marketing to create and complete the artwork quickly will result in more mistakes being made. Additionally, this will cause delays to production and result in unfulfilled requirements for L'Oreal's business-to-business customers.

The additional time it takes to complete an artwork from the stage the change has been requested is shown in Figure 9. For example, if the supplier (stage 7, Table 2) requests a change to be made, adds 7-17 extra working days to the lead-time, having a knock-on effect on all the subsequent stages in the process. However, if some of the stages in the current VSM are eliminated, then the lead-time to complete amendments will be significantly reduced. The proposed changes will be discussed in the following section.

\section{"Bring in Figure 9"}

\subsection{Proposed Changes to Current VSM}

The codes launch and the factory manually enter in stages 2 and 3 will be automatically pulled from the product code sheets. Additionally, stages 5, 8, 9 and 11 currently act as a 'messenger', by sending the PDF file to the next stage, adding little value to the process. Instead, with an automated system, each function will have visibility on the status and progress of artworks and a new critical path created. As a result, this will significantly 
reduce the lead-time and free up more time in the process, potentially removing up to 23 days. As a result, the process will be leaner and more agile to respond to changes and the requirements of business-to-business customers. Furthermore, an automated system will track the dates and times each function completes their steps and highlight when deadlines are being missed and who is accountable. This extra data should be used in the future to accurately allocate resources to each brand. Furthermore, this will remove duplicate work as each function currently tracks artworks independently from other functions and brands. Therefore, it is proposed that stages 2,3,5,8,9, and 11 in the current VSM be automated using API. This will be achieved by connecting the local country's product code sheet to a bespoke system.

\subsection{Proposed VSM}

Table 3 and Table 4 illustrate the Proposed VSM. A Proposed VSM has eliminated 6 out of 12 stages from the Current VSM (Table 1 and 2), which resulted in a 50 percent reduction in the total number of stages. Automated stages are illustrated in the blue star bubble in Tables 3 and 4. Furthermore, the proposed process would no longer use email; therefore the email icon is shown in the blue star bubble. Instead, a bespoke system would allow the artwork PDF files to be uploaded onto the system and automatically forwarded to the correct contact, significantly reducing human error. Additionally, the system would be split by brand and users would be given access to the necessary sections, where the codes, deadlines and current progress would be displayed. As a result, when someone is on annual leave or off sick another team member would be able to immediately access the necessary information to continue the work; ensuring deadlines are not being missed. Table 3 and 4 shows, an amendment at stage 6 would return to stage 2 or 5 depending on the required change. 
Furthermore, the SLA collected from 12 L'Oreal employees has been used to illustrate the lead-time to complete the artwork with an automated system. Currently, it takes a minimum of 23 days and a maximum of 51 days to complete an artwork. However, with an automated system, this is reduced to a minimum of 17 days and a maximum of 36 days, resulting in an average decrease of 10.5 days per artwork. Moreover, this reduction would significantly reduce the number of missed deadlines, which would enable all the subsequent stages to be more responsive to meet the requirements of business-tobusiness customers (Rodriguez and Molina, 2018).

Furthermore, the average VA and NVA for the current VSM and the proposed VSM are compared. This is illustrated in Figure 10. The VA for a renovation has increased by $2.48 \%$ to $4.31 \%$. Additionally, the VA for NPD has increased from $2.52 \%$ to $4.41 \%$. As a result, the proposed VSM shows a $73 \%$ increase in value added time for a renovation and a $75 \%$ increase in value added time for NPD (Figure 10).

"Bring in Figure 10"

\subsection{Amendments Comparison: Current VSM and Proposed VSM}

Figure 11 shows the added time for amendments calculated from the Current VSM and Proposed VSM (Tables 1, 2, 3 and 4). The Current VSM shows that one amendment adds up to 36 days in the artwork process (Stage 12 back to 4, Figure 11). 
This has been reduced to 25 days in the Proposed VSM (Figure 11), which is a reduction of 11 days. On average, the Current VSM amendment adds 13 days to the process, in the Proposed VSM, this has been reduced to 10 days. This illustrates that a leaner system would reduce the lead times by eliminating inefficient stages in the AP. Additionally, the AP would become more agile as each function would be more responsive as time has been freed up in the process (Jacobs and Chase, 2017).

\section{"Bring in Figure 11"}

\subsection{Validation of Proposed VSM}

Feedback in the form of qualitative responses was used in order to validate the Proposed VSM. Feedback from 9 L'Oreal employees in different levels on seniority from the launch, factory and marketing teams was collected. This was to evaluate whether VSM would pinpoint where the process should be improved. Respondents were asked what causes the most delays in the artwork process. Respondents in all functions suggested that "using email to transmit the files causes delays" in their role. Furthermore, the factory commented that there was a "high risk of losing these files on email" and "if someone went on annual leave the artwork process is significantly delayed". Additionally, respondents in launch and marketing both highlighted making amendments as a significant delay.

Secondly, respondents were asked if an automated system would improve these delays. All respondents confirmed that an automated system would improve delays and have a positive impact on their roles. Furthermore, in response to this question, the supply chain manager in the Consumer Products division replied, "yes! 100\%. To track progress and to know which project is at which stage, what is late etc. would be very helpful". 
Respondents from the factory and marketing commented that implementing an automated system would allow them to have "greater visibility on the tasks that need completing", which will help them to "prioritize their work". Additionally, launch commented that this would significantly reduce the amount of time wasted inputting data manually.

Furthermore, when asked what disadvantages an automated system would have on their role, one factory respondent commented that a clear RACI (Responsible, Accountable, Consulted and Informed) needed to be implemented to make sure the correct recipients are aware of the work they are responsible for. The launch intern commented that they may have "less control over the process" and that the "process would be less easy to manipulate". In response to this, if an automated system replaced the current process, then the process would need to be agile, to be flexible to the incorporate amendments in the AP (Rodriguez and Molina, 2018; Jacobs and Chase, 2017).

Furthermore, respondents were asked 'what should be improved on the Proposed VSM'? Unfortunately, most of the respondents lacked understanding on lean concepts and VSM. This was a common issue found in the literature review (Hines et al., 1998). However, one factory manager suggested that the Proposed VSM should be improved to "show the time saved from the automation and elimination of stages on the map". Therefore, a final VSM has been created to illustrate the time saved on the Proposed VSM. Table 5 and Table 6 include the cumulative number of days saved, shown as a green line on the Final Proposed VSM.

Additional comments suggested that it would be helpful to have alerts on the system to tell the contact when a deadline is approaching for work that has not yet been completed. 
Other comments from the respondents representing the launch and marketing teams, highlighted that they felt the deadlines given were unrealistic and did not give sufficient time for the work to be completed. Though the implementation of an automated system will enable the collection of data, which should be analyzed to accurately evaluate whether the deadlines given by the factory allow sufficient time.

"Bring in Tables 5 \& 6" 


\subsection{Discussion}

The cause and effect diagram (Figure 8) highlights causes that should be eliminated if an automated system was put in place. Missed work from annual leave, sickness and handovers should be eliminated, as an automated system using API would accurately store the information and status of artworks and enable others to view and work on the tasks. Additionally, human error would be minimized such as the loss of artworks, which was raised as a significant issue in the feedback from L'Oreal's employees. However, to implement a new process, senior levels of management would need to be educated on VSM and lean concepts and its benefits, as it was clear from the feedback that there was a lack of understanding of VSM, which is consistent with the issues stated in the literature review (Hines et al., 1998). Additionally, the costs of implementing a bespoke system may also be a strong factor in senior managements buy in (Zubkova and Tagirova, 2019).

\subsection{Conclusion and Further Research}

In conclusion, VSM within the concept of lean has successfully identified the inefficiencies in the process and highlighted the stages in the process that should be removed or automated using API. As a result, a new critical path was created which illustrated a average reduction of $28 \%$ of time spent on the AP, and an average saving of 10.5 days per artwork created, enabling L'Oreal to maximize their value adding activities. Additionally, the value added time has increased by $73 \%$ for a renovation and $75 \%$ for NPD as a result of the proposed VSM. Additionally, stages in the proposed VSM have been reduced by $50 \%$ by removing 6 stages out of 12 from the current VSM. Such a high reduction enables the process to become more agile, as each function has more time to respond to amendments and changes in the AP. This has also resulted in an average reduction in the time it takes for amendments to be completed from 13 days to 10 days. It 
is not clear from the data whether the factory is allowing enough time or whether marketing is lacking in resources. An automated system has the ability to give visibility so that this issue will be solved, by collecting and analyzing the data obtained through an automated system. Additionally, human error often occurs in the AP and results in extra destructions costs, by automating the system these costs will be significantly reduced. As a result, it is recommended that L'Oreal implement an automated system to reduce lead times, maximize VA activities, eliminate NVA activities and reduce human error. As a result, the AP will be more responsive and flexible in meeting the requirements of its business-tobusiness customers (Rodriguez and Molina, 2018; Jacobs and Chase, 2017). Furthermore, this process is just one communication flow of artworks in Europe, further research into the 12 other countries (Figure 1) should be explored to create a bespoke system that allows for synergy across the countries in Europe. It is expected that using VSM for each communication flow for each country, will likely show the same benefits of reduced lead-times, waste elimination and value maximization. Moreover, there are different brands and divisions in L'Oreal across Europe, which would equally benefit from a standardized AP. However, further research would need to be conducted and developed in these areas. Therefore, further research should be carried out to evaluate the total spend on destruction costs in the U.K. Moreover, this analysis should be expanded to include the costs incurred by other countries in Europe to better understand the costs of investing in a bespoke system for the AP. 


\section{$\underline{\text { References }}$}

Al Hroub, A., Obaid, A., Yaseen, R., El-Aqoul, A. Zghool, N., Abu-Khudair, H., Alloubani, A. (2019), "Improving the Workflow Efficiency of An Outpatient Pain Clinic at A Specialized Oncology Center by Implementing Lean Principles", Asia-Pacific Journal of Oncology Nursing, Vol 6 No. 4, pp. 381-387.

Braglia, M., Carmignani, G. and Zammori, F. (2006), "A new value stream mapping approach for complex production systems", International Journal of Production Research, Vol. 44, No. 18-19, pp. 3929-3952.

Camgoz-Akdag, H., Caliskan, E. and Toma, S. (2017), "Lean process design for a radiology department", Business Process Management Journal, Vol. 23 No. 4, pp. 779-791.

Dadashneiad, A. and Valmohammadi, C. (2018), "Investigating the effect of value stream mapping on operational losses: a case study". Journal of Engineering, Design and Technology, Vol 16 No. 3, pp. 478-500.

Denning, S. (2016), "How to make the whole organization Agile". Strategy \& Leadership, Vol 44 No. 4, pp. 10-17.

Dinis-Carvalho, J., Guimaraes, L., Sousa, R. and Leao, C. (2019), "Waste identification diagram and value stream mapping: A comparative analysis", International Journal of Lean Six Sigma, Vol. 10 No. 3, pp. 767-783. 
Foster, M.N. and Rhoden S.L.N.H. (2020), "The integration of automation and artificial intelligence into the logistics sector: A Caribbean perspective", Hospitality and Tourism Themes, Vol. 12, No. 1, pp. 56-68.

Garfalkar, M., Ali, Z. and Hillier G. (2017), "Measuring resource efficiency and resource effectiveness in manufacturing", International Journal of performance and production management, Vol 67 No. 9, pp. 1854-1881.

Hines, P., Rich, N. and Bicheno, J. (1998), "Value Stream Management", The International Journal of Logistics Management, Vol 9, pp. 25-42.

Hines, P. and Rich, N. (1997), "The Seven Value Stream Mapping Tools" International Journal of Operations \& Production Management, Vol 17 No. 1, pp. 46-64.

IBM. 2020. "IBM: API connect", available at: https://www.ibm.com/uken/cloud/api-connect (Accessed February 11, 2020).

Jacobs, F. and Chase, R. (2017), "Operations and Supply Chain Management", McGraw-Hill Education, New York, NY.

Jatsi, K. and Sharma, A. (2013), "Lean Manufacturing Implementation Using Value Stream Mapping as a Tool", International Journal of Lean Six Sigma, Vol 5 No.1, pp. 89-116.

Jones, D., Hines, P. and Rich, N. (1997), "Lean logistics", International Journal of Physical Distribution \& Logistics Management, Vol. 27 No. 3, pp. 153-173. 
Kale, S. and Parikh, R. (2019), "Lean Implementation in a Manufacturing Industry through Value Stream Mapping". International Journal of Engineering and Advanced Technology, Vol 8 No.6, pp. 908-913.

Kumar, M., Garg, D. and Agarwal, A. (2019), "An analysis of inventory attributes in leagile supply chain: cause and effect analysis", International Journal of Mathematical Engineering and Management Sciences, Vol 4 No.4, pp. 870881.

Kumar, S., Dhingra, A. and Singh, B. (2018), "Lean-Kaizen implementation: A roadmap for identifying continuous improvement opportunities in Indian small and medium sized enterprise", Journal of Engineering, Design and Technology, Vol. 16 No. 1, pp. 143-160.

Lugert, A., Batz, A. and Winkler, H. (2018), "Empirical assessment of the future adequacy of value stream mapping in manufacturing industries", Journal of Manufacturing Technology Management, Vol. 29 No. 5, pp. 886-906.

Matt, D. (2014), "Adaptation of the value stream mapping approach to the design of lean engineer-to-order production systems: A case study", Journal of Manufacturing Technology Management, Vol. 25 No. 3, pp. 334-350.

Microsoft. 2020. "Microsoft Customers: Walgreens", available at: https://customers.microsoft.com/en-gb/story/778746-walgreens-retailersazure-analytics (Accessed February 11, 2020). 
Microsoft. 2020. "Microsoft Customers: HP", available at: https://customers.microsoft.com/en-gb/story/hp-manufacturing-microsoft-ai (Accessed February 11, 2020).

Microsoft. 2020. "Microsoft Customers: ASOS", available at: https://customers.microsoft.com/en-gb/story/asos-retail-and-consumer-goodsazure (Accessed February 11, 2020).

MuleSoft, 2019. "MuleSoft", available at: https://www.mulesoft.com/resources/api/what-is-an-api (Accessed December 11, 2019).

Rodriguez, D. and Molina, E. (2018), "The experience of implementation with Agile Business Process Management", Advances in Science, Technology and Engineering Systems, Vol 3 No.4, pp. 284-294.

Rother, M. and Shook, J. (1998), "Learning to See: Value Stream Mapping to Create Value and Eliminate Muda", Lean Enterprise Institute, Brookline, Cambridge.

Russell, R.S. and Taylor, B.W. (2020) "Operations and Supply Chain Management", $10^{\text {th }}$ Edition, John Wiley \& Sons.

Saboo, A., Garza-reyes, J., Er, A. and Kumar, V. (2014), "A VSM improvementbased approach for lean operations in an Indian manufacturing SME", International Journal of Lean Enterprise Research, Vol 1 No.1, pp. 41-58. 
Schroder, R. and Goldstein S (2020), “Operations Management in the Supply Chain: decisions and cases", $8^{\text {th }}$ Edition, McGraw-Hill Education, New York, NY.

Serrano-Lasa, I., Ochoa-Laburu, C. and de Castro Vila, R. (2008), "An evaluation of the value stream mapping tool", Business Process Management Journal, Vol. 14 No. 1, pp. 39-52.

Seth, D., Seth, N. and Goel, D. (2007), "Application of value stream mapping (VSM) for minimization of wastes in the processing side of supply chain of cottonseed oil industry in India context", Journal of manufacturing technology management, Vol. 19, No.4, pp. 529-550.

Singh, B., Garg, S.K. and Sharma, S.K. (2011), "Value stream mapping: literature review and implications for Indian industry", International Journal of Advanced Manufacturing Technology, Vol. 53, No. 5-8, pp. 799-809.

Singh, J., Singh, H., Singh, A. and Singh, J. (2019), "Managing industrial operations by lean thinking using value stream mapping and six sigma in manufacturing unit: Case studies", Management Decision, Vol. 58, No. 6, pp. 1118-1148.

Solaimani, S., Talab, A. Rhee, B. (2019), "An integrative view on Lean innovation management”, Journal of Business Research, Vol 105, pp. 109-120. 
Suarez-Barraza, M., Miguel-Davila, J. and Vasquez-Garcia, C. (2016), "Supply Chain value stream mapping: a new tool of operations management", International Journal of Quality \& Reliability Management, Vol. 33 No. 4, pp. 518-534.

Vinodh, S., Somanaathan, M. and Arvind, K. (2013), "Development of value stream map for achieving leanness in a manufacturing organization", Journal of Engineering, Design and Technology, Vol. 11 No. 2, pp. 129-141.

Zubkova, T. and Tagirova, L. (2019), "Intelligent user interface design of application programs", Journal of Physics: Conference Series. 2-9. 


\section{List of Figures}

\begin{tabular}{|l|}
\hline Labels for different countries \\
\hline FR - France \\
\hline DFSN, Denmark, Finland, Sweden, \\
Netherlands \\
\hline GB, Great Britain \\
\hline DE, Germany \\
\hline GR, Greece \\
\hline PO, Poland \\
\hline PT, Portugal \\
\hline CZ, Czech Republic \\
\hline IT, Italy \\
\hline HU, Hungary \\
\hline ES, Spain \\
\hline BG, Bulgaria \\
\hline
\end{tabular}

Figure 1. Countries that produce their own labels

\begin{tabular}{|ll|}
\hline Factory & Produces \\
\hline Aulnay, France & Tubes \\
\hline Ramboulillet, France & Bottles \\
\hline OMA, France & L'Oreal Paris makeup \\
\hline Soprocos/ St Quentin, France & Aerosols \\
\hline Kosmepol/Varsovie/Warsaw, Poland & Shampoo and Conditioner \\
\hline Karlrushe, Germany & Pots \\
\hline Israel & Oils and Serums \\
\hline Libramont, Belgium & Colorants \\
\hline Settimo, Italy & Shampoo and Conditioner \\
\hline
\end{tabular}

Figure 2. Factories in Europe and what they produce 


\begin{tabular}{|c|c|c|c|c|}
\hline Stage & \multicolumn{2}{|c|}{ SLA No. Of days } & \multicolumn{2}{|c|}{$\begin{array}{l}\text { Time to complete task } \\
\text { (minutes) }\end{array}$} \\
\hline 1 Development & $1-3$ & & 3 & \\
\hline 2 Factory & $1-5$ & & 3 & \\
\hline 3 Launch & $1-2$ & & 3 & \\
\hline 4 Marketing & (A) 3-5 & (B) $10-15$ & (A) 180 & (B) 600 \\
\hline 5 Launch & \multicolumn{2}{|l|}{$1-2$} & \multicolumn{2}{|l|}{5} \\
\hline 6 Factory & \multicolumn{2}{|l|}{$1-5$} & \multicolumn{2}{|l|}{5} \\
\hline 7 Supplier & \multicolumn{2}{|l|}{$5-10$} & \multicolumn{2}{|l|}{90} \\
\hline 8 Factory & \multicolumn{2}{|l|}{$1-5$} & \multicolumn{2}{|l|}{3} \\
\hline 9 Launch & \multicolumn{2}{|l|}{$1-2$} & \multicolumn{2}{|l|}{3} \\
\hline 10 Marketing & \multicolumn{2}{|l|}{$1-5$} & \multicolumn{2}{|l|}{60} \\
\hline 11 Launch & \multicolumn{2}{|l|}{$1-2$} & \multicolumn{2}{|l|}{5} \\
\hline 12 Factory & \multicolumn{2}{|l|}{$1-5$} & \multicolumn{2}{|l|}{5} \\
\hline
\end{tabular}

Figure 3: The service level agreement (SLA) and time to complete a task

\begin{tabular}{|c|c|c|c|c|c|c|c|c|c|c|c|}
\hline Brand & Material Code & Description & EAN & Date Received & AW Deadline & AW - Launch & AW - Factory & BAG Deadline B & BAG - Marketing & BAG - Launch & BAG - Factory \\
\hline-1 & $\nabla$ & $\nabla$ & $\nabla$ & $\nabla$ & $\nabla$ & $\nabla$ & $\nabla$ & $\nabla$ & $\nabla$ & $\nabla$ & $\nabla$ \\
\hline Garnier Haircare & C6013101 & UD ASH CRANBERRY 360 GB DF & 3600542133470 & 21-Feb & 08-Mar & 17-Apr & 17-Apr & 20-May & 14-May & 22-May & 22-May \\
\hline Garnier skincare & C4444752 & S.ACT BB ANTI AGE $12 \mathrm{H}$ T50 GB LGHT & 3600541227897 & 20-Aug & 30-Aug & 31-Aug & 31-Aug | & 01-Oct & 26-Sep & 25-0ct & $25-0 c t$ \\
\hline Garnier skincare & C5505753 & S. ACT BB PURE ACT T50 GB light & 3600541480049 & 20-Aug & 30-Aug & 31-Aug & 31-Aug & 31-0ct & 29-0ct & 30-0ct & 30-0ct \\
\hline Garnier skincare & C5926002 & S.ACT BB CR.NATURAL TSO EN LIGHT & 3600542091954 & 20-Aug & 30-Aug & 31-Aug & 31-Aug | & $17-0 c t$ & 15-Oct & 23-0ct & 23-Oct \\
\hline Garnier skincare & C4341652 & S.ACT BB OIL FREE $12 \mathrm{H}$ T40 GB MEDIUM & 3600541194427 & 20-Aug & 30-Aug & 31-Aug & 31-Aug | & 04-Sep & 28-Sep & 23-Oct & 23-Oct \\
\hline Garnier skincare & C5926102 & S.ACT BB CR.NATURAL TSO EN MEDIUM & 3600542091961 & 20-Aug & 30-Aug & 31-Aug & 31-Aug | & $17-0 c t$ & 15-Oct & 23-0ct & 23-0ct \\
\hline Garnier skincare & C4341552 & S.ACT BB OIL FREE $12 \mathrm{H}$ T40 GB LIGHT & 3600541194410 & 20-Aug & 30-Aug & 31-Aug & 31-Aug | & $03-0 \mathrm{ct}$ & 02-Oct & 23-Oct & 23-Oct \\
\hline Garnier skincare & C6253900 & Garnier Tissue Mask Crow Feet Eye & 3600542238632 & 29-Nov & 07-Dec & 14-Jan & 14-Jan & 15-Dec & 28-Jan & 29-Jan & 29-Jan \\
\hline LP Haircare & A7428452 & ELVIVE EXTRAORD OIL MASK POT $300 \mathrm{ml}$ & 3600522451815 & 29-0ct & 14-Nov & 28-Nov & 28-Nov & 07-Dec & 05-Dec & 06-Dec & 06-Dec \\
\hline LP skincare & A9199200 & Revitalift Filler Eyes $15 \mathrm{ml}$ & 3600523201310 & 23-Jul & 31-Jul & 17-Sep & 20-Sep & 15-Oct & 09-0ct & $12-0 c t$ & $12-0 \mathrm{ct}$ \\
\hline LP skincare & A9816700 & AP Golden Age Rosy Eye $15 \mathrm{ml}$ & 3600523718597 & 10-Aug & 31-Aug & 04-Sep & 04-Sep & 11-Oct & 05-Oct & 01-Nov & 01-Nov \\
\hline LP skincare & A8671900 & DE REV FILL HA NUIT PO5O EN_FD & 3600523201303 & 20-Aug & 31-Aug & 11-Sep & 11-Sep & $03-0 \mathrm{ct}$ & 28-Sep & $12-0 \mathrm{ct}$ & $12-0 \mathrm{ct}$ \\
\hline LP skincare & A9200101 & DE Revitalift Laser Eye $15 \mathrm{ml}$ 2nd Run & 3600522251750 & 26-Sep & 04-0ct & 05-Oct & 15-Oct & $29-0 \mathrm{ct}$ & 30-Oct & 31-Oct & 31-Oct \\
\hline LP skincare & A9020600 & Dermo Hydra Genius Waters $70 \mathrm{ml} \mathrm{N} / \mathrm{C}$ & 3600523363186 & 19-0ct & 29-Oct & 08-Nov & 08-Nov & 05-Dec & 29-Nov & 03-Dec & 03-Dec \\
\hline LP skincare & A9186500 & EXT CLAY FOAM TU150 EN EXFOLIATING & 3600523430925 & 14-Nov & 20-Nov & 03-Jan & 03-Jan & 18-Jan & 14-Jan & 18-Jan & 18-Jan \\
\hline LP skincare & A9228900 & DE FF CLEANSING MILK D/S $400 \mathrm{ml}$ & 3600523448760 & 14-Jan & 21-Jan & $07-\mathrm{Feb}$ & $07-\mathrm{Feb}$ & 25 -Feb & 21-Feb & $27-\mathrm{Feb}$ & $27-\mathrm{Feb}$ \\
\hline LP skincare & A5743153 & Dermo Exp Eye Make Up Remover $125 \mathrm{ml}$ & 5011408014341 & 04-Jan & 18-Jan & 23-Jan & 23-Jan & 28-Mar & 22-Mar & 04-Apr & 04-Apr \\
\hline Sun \& Body & C3575617 & AS Clear Spray SPF50+200ml 17 & 3600541012103 & 21-Sep & 03-Oct & 05-Oct & 05-Oct & 21-Nov & 20-Nov & 03-Dec & 03-Dec \\
\hline
\end{tabular}

Figure 4: Sample of data from the artwork tracker

\section{Comments/Status}

Capital $\mathrm{C}$ needs to be amended - otherwise approved 08/05

Spelling mistakes - can be fixed without doc or DDR 16/05

BAG resent (amended)

Ai \& Vectorised files

Made in

London W6 8AZ

changes the size of the flame

Marketing want to change AW - sent this across the $01 / 02$

BAG formula incorrect $27 / 05$

rejected $200 \mathrm{ml} / 300 \mathrm{ml}$ mask

Figure 5: Sample of comments on the artwork tracker 


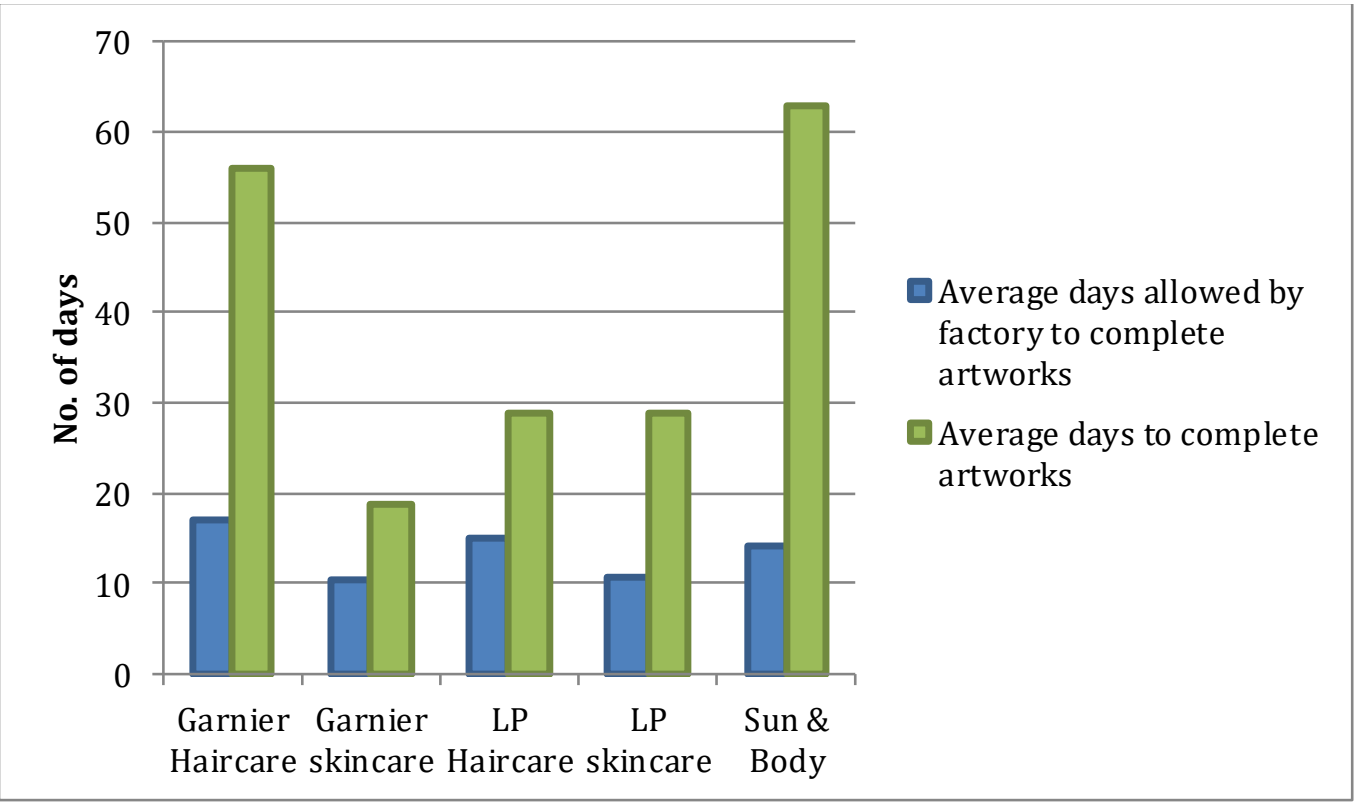

Figure 6: Average time to complete artworks

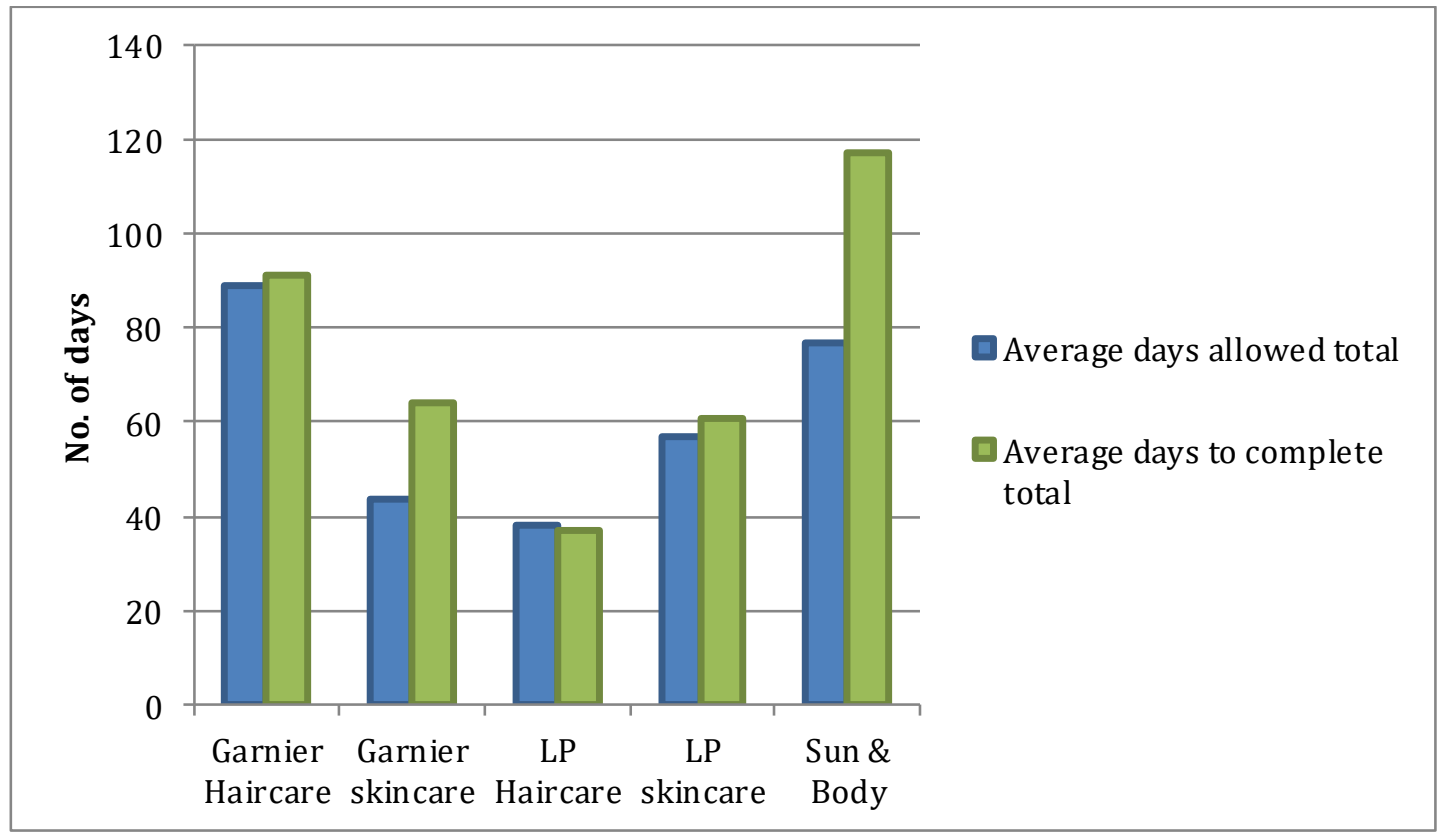

Figure 7: Average time to complete an artwork and average time allowed by the factory 


\section{Cause and Effect Diagram}

Incorrect

Missed in

information

handover

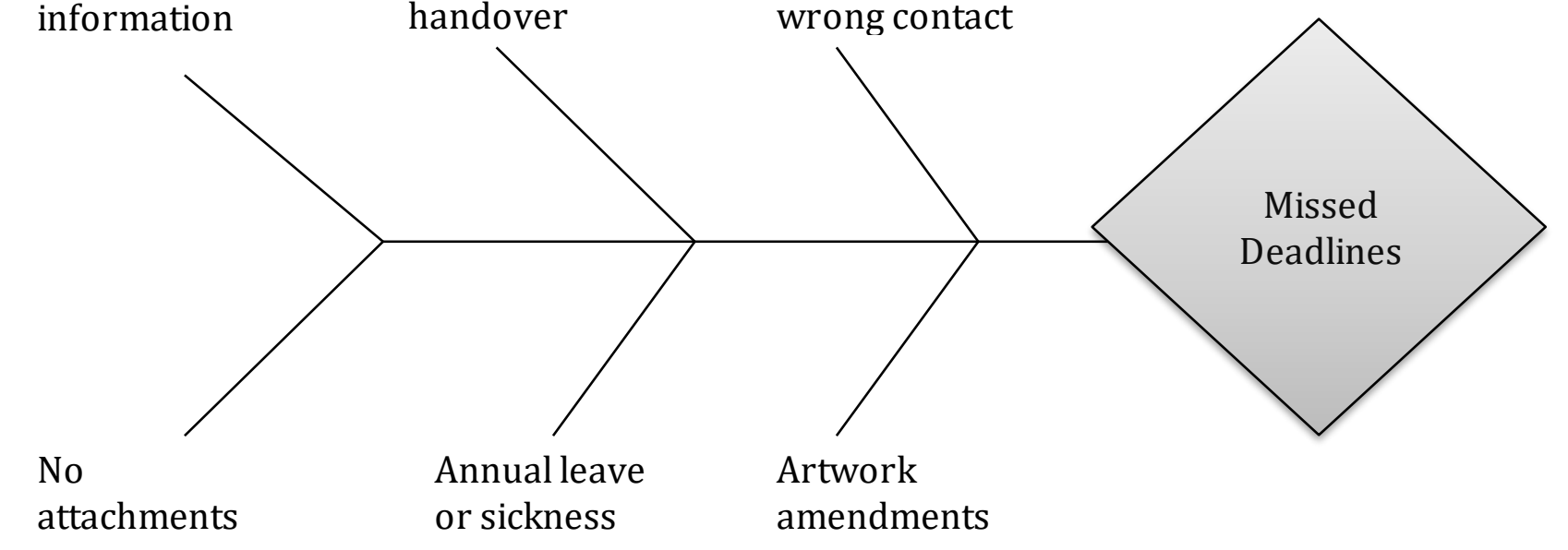

No
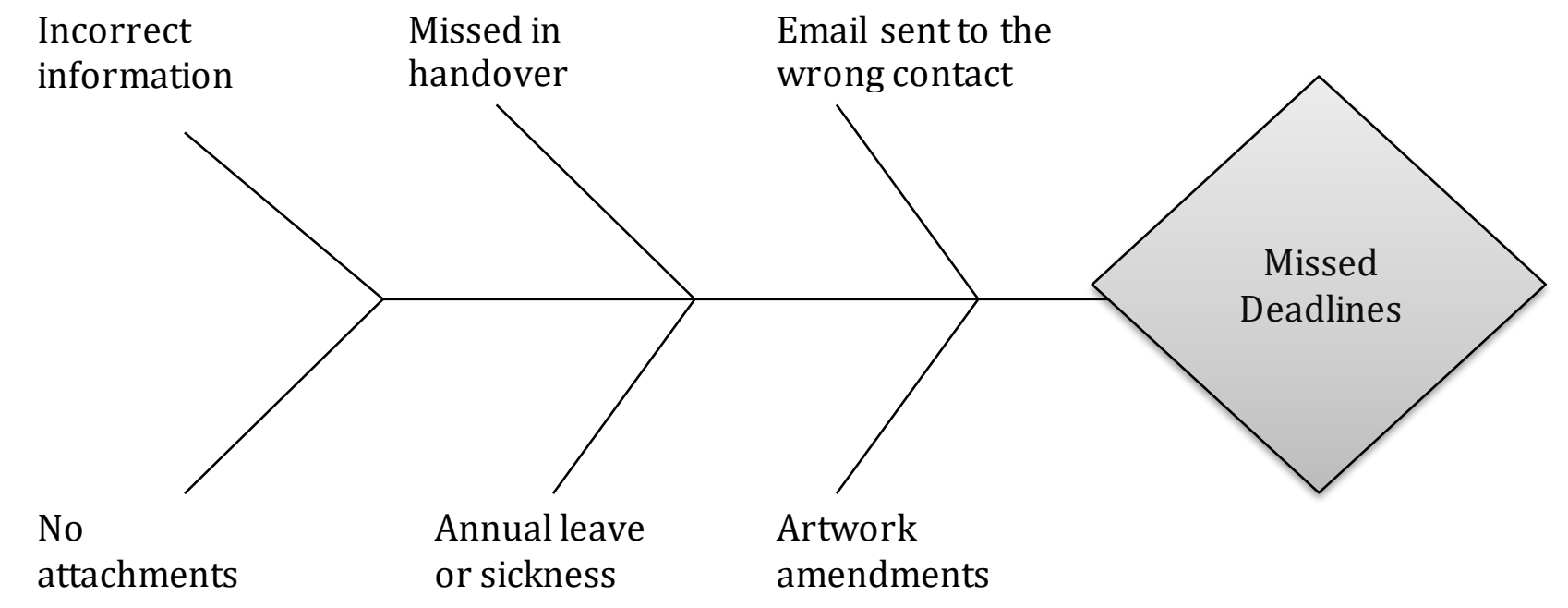

Email sent to the
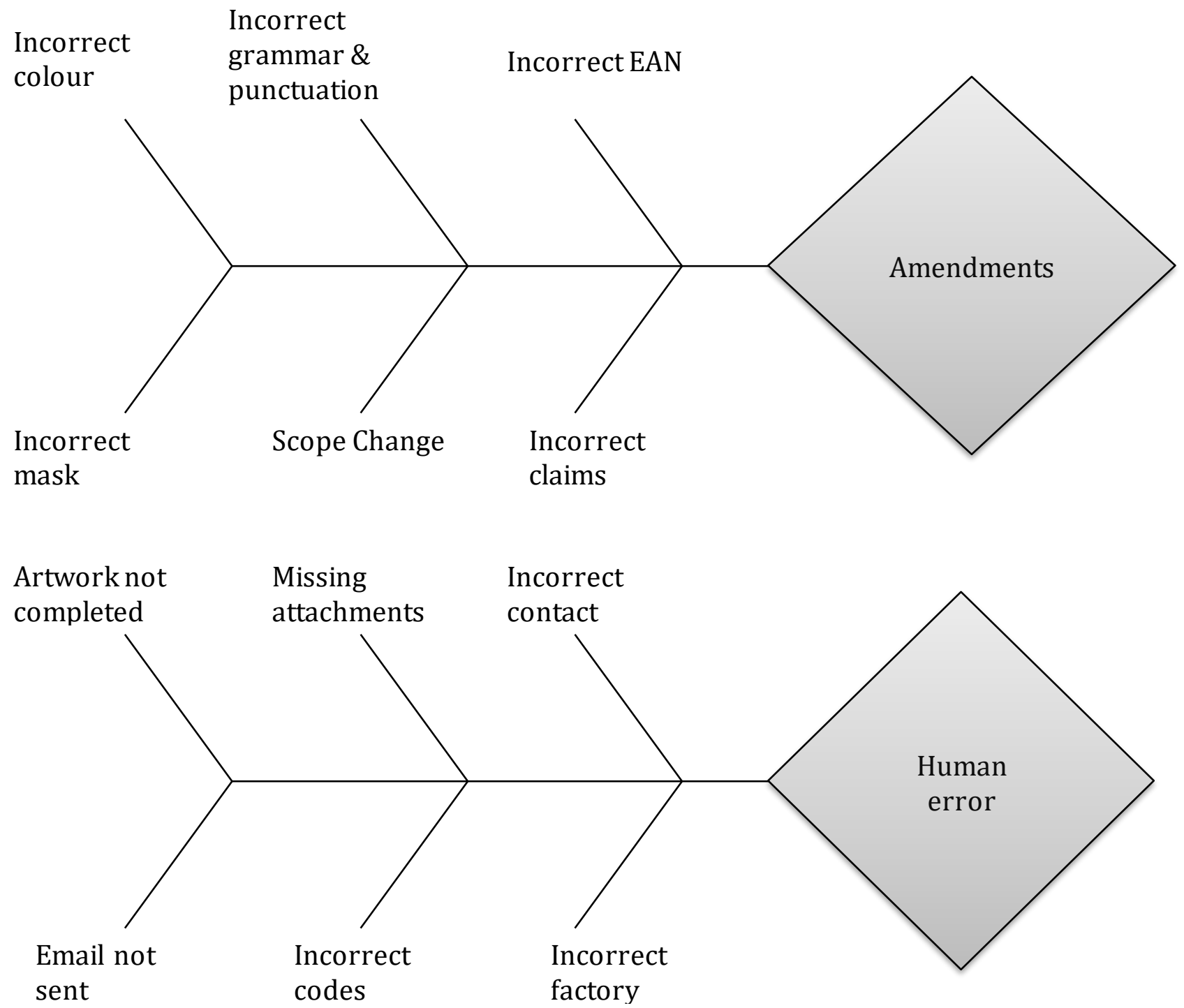

Figure 8: Cause and Effect Diagram for artwork delays 


\begin{tabular}{|c|c|c|}
\hline \multicolumn{3}{|c|}{ Amendments } \\
\hline & Stage & Added time in days \\
\hline \multirow{9}{*}{$\begin{array}{l}\text { Current VSM } \\
\text { (Table } 1 \text { and 2) }\end{array}$} & 5 back to 4 & $1-2$ \\
\hline & 6 back to 4 & $2-7$ \\
\hline & 7 back to 4 & $7-17$ \\
\hline & 8 back to 4 & $8-22$ \\
\hline & 9 back to 4 & $9-24$ \\
\hline & 10 back to 4 & $10-29$ \\
\hline & 11 back to 4 & $11-31$ \\
\hline & 12 back to 4 & $12-36$ \\
\hline & 8 back to 7 & 5 \\
\hline
\end{tabular}

Figure 9: Added lead-time for amendments - Current VSM

\begin{tabular}{|l|l|l|l|l|l|}
\hline $\begin{array}{l}\text { Artwork } \\
\text { Type }\end{array}$ & $\begin{array}{l}\text { Current } \\
\text { VA }\end{array}$ & $\begin{array}{l}\text { Current } \\
\text { NVA }\end{array}$ & $\begin{array}{l}\text { Proposed } \\
\text { VA }\end{array}$ & $\begin{array}{l}\text { Proposed } \\
\text { NVA }\end{array}$ & $\begin{array}{l}\text { Percentage } \\
\text { change in } \\
\text { VA }\end{array}$ \\
\hline $\begin{array}{l}\text { Renovation } \\
\text { (A) }\end{array}$ & $2.48 \%$ & $97.52 \%$ & $4.31 \%$ & $95.67 \%$ & $73 \%$ \\
\hline NPD (B) & $2.52 \%$ & $97.48 \%$ & $4.41 \%$ & $95.59 \%$ & $75 \%$ \\
\hline
\end{tabular}

Figure 10: VA and NVA for the Current and Proposed VSM 


\begin{tabular}{|c|c|c|}
\hline \multicolumn{3}{|c|}{ Amendments } \\
\hline & Stage & Added time in days \\
\hline \multirow{9}{*}{$\begin{array}{l}\text { Current VSM } \\
\text { (Table } 1 \text { and 2) }\end{array}$} & 5 back to 4 & $1-2$ \\
\hline & 6 back to 4 & $2-7$ \\
\hline & 7 back to 4 & $7-17$ \\
\hline & 8 back to 4 & $8-22$ \\
\hline & 9 back to 4 & $9-24$ \\
\hline & 10 back to 4 & $10-29$ \\
\hline & 11 back to 4 & $11-31$ \\
\hline & 12 back to 4 & $12-36$ \\
\hline & 8 back to 7 & 5 \\
\hline \multirow{5}{*}{$\begin{array}{l}\text { Proposed VSM } \\
\text { (Table } 3 \text { and } 4 \text { ) }\end{array}$} & 3 back to 2 & $1-5$ \\
\hline & 4 back to 2 & $6-15$ \\
\hline & 5 back to 2 & $7-20$ \\
\hline & 6 back to 2 & $8-25$ \\
\hline & 6 back to 5 & $1-5$ \\
\hline
\end{tabular}

Figure 11: Current VSM and Proposed VSM added lead-time for amendments 
$A=$ Renovation

$\mathrm{B}=\mathrm{NPD}$

$\mathrm{VA}(\mathrm{A})=$ Value Added Renovation

NVA (A) = Non-Value Added Renovation

VA (B) = Value Added NPD

NVA $(B)=$ Non-Value Added NPD
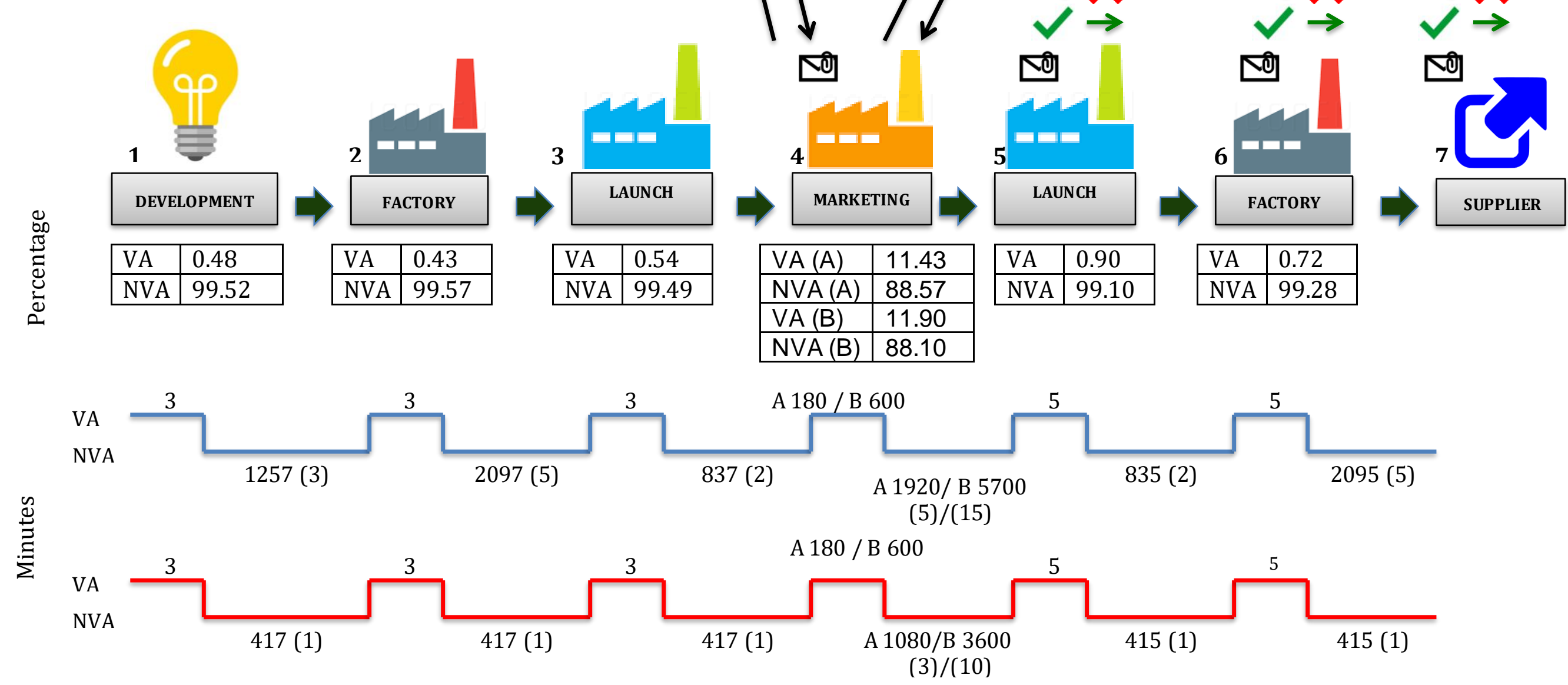


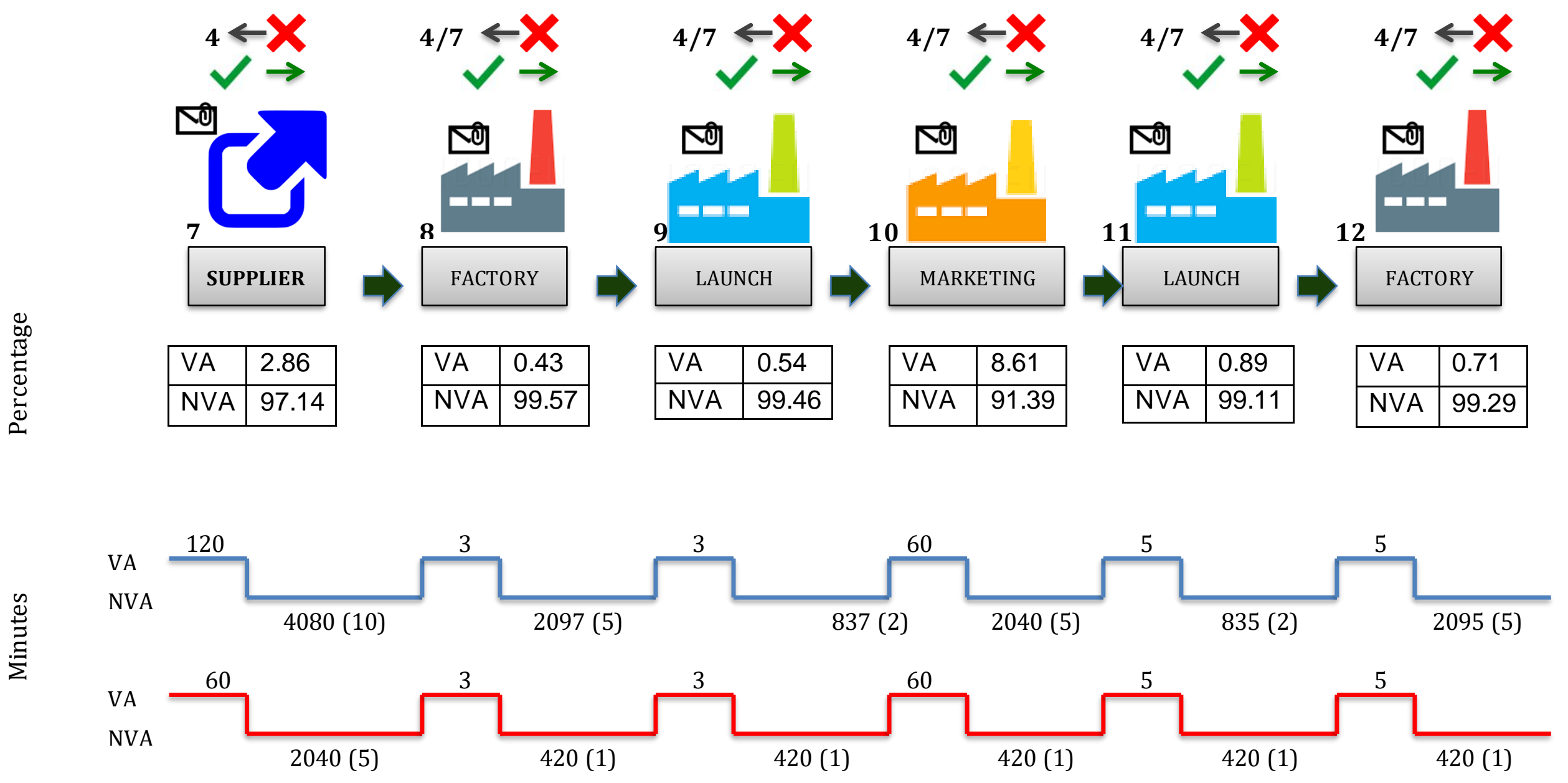




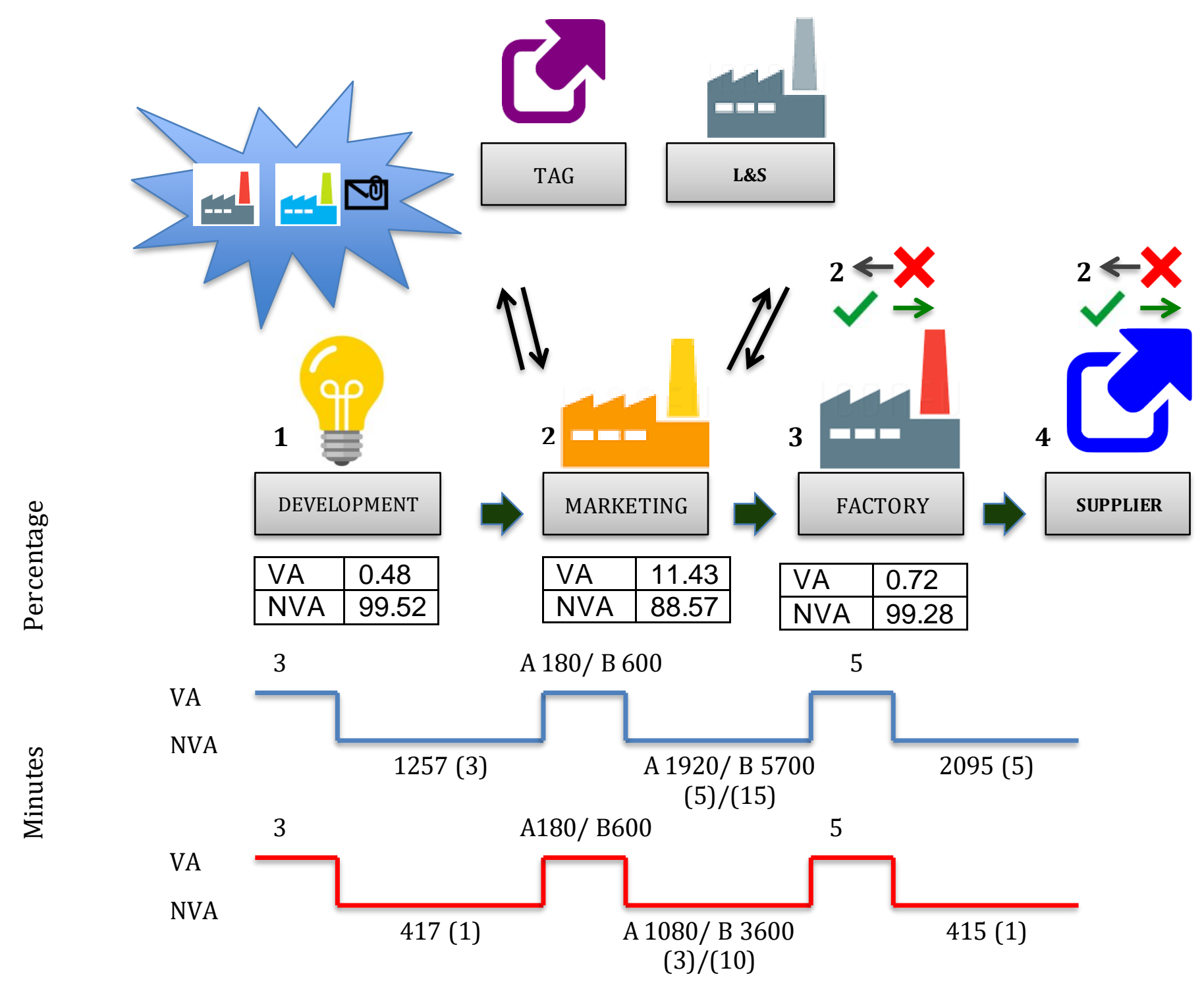




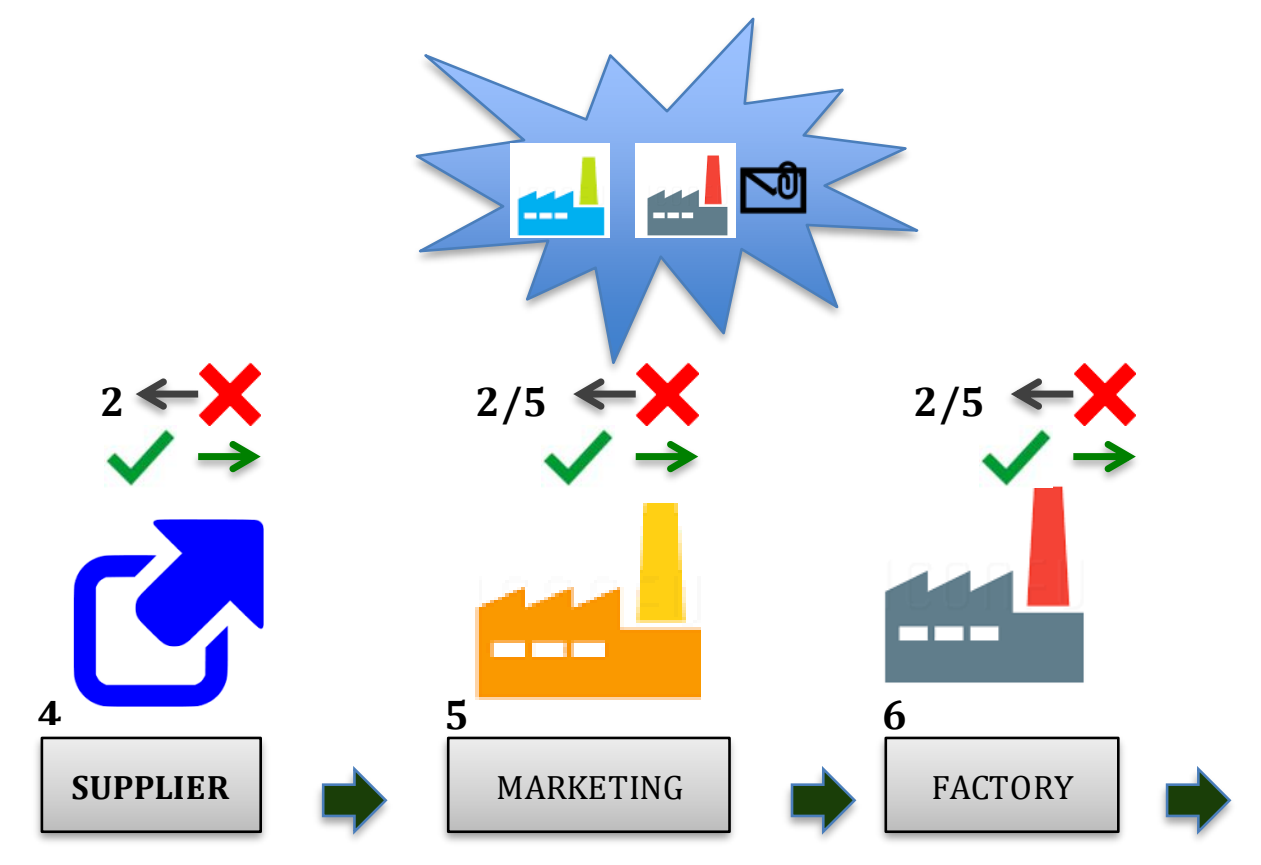

D.

\begin{tabular}{|l|l|}
\hline VA & 2.86 \\
\hline NVA & 97.14 \\
\hline
\end{tabular}$\quad$\begin{tabular}{|l|l|}
\hline VA & 8.61 \\
\hline NVA & 91.39 \\
\hline
\end{tabular}$\quad$\begin{tabular}{|l|l|}
\hline VA & 0.71 \\
\hline NVA & 99.29 \\
\hline
\end{tabular}

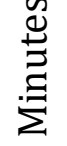

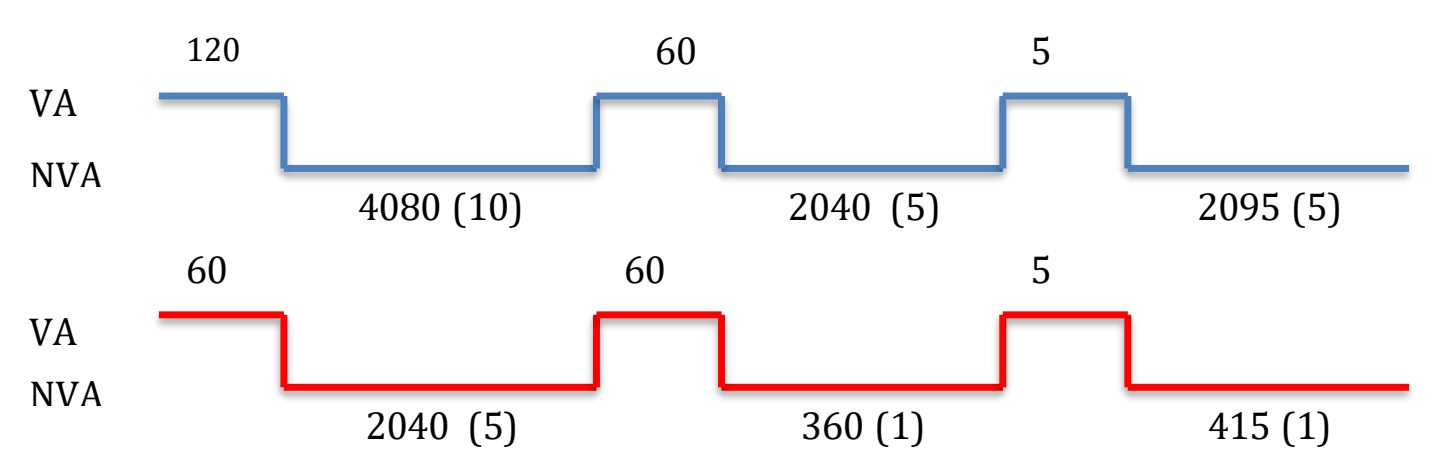




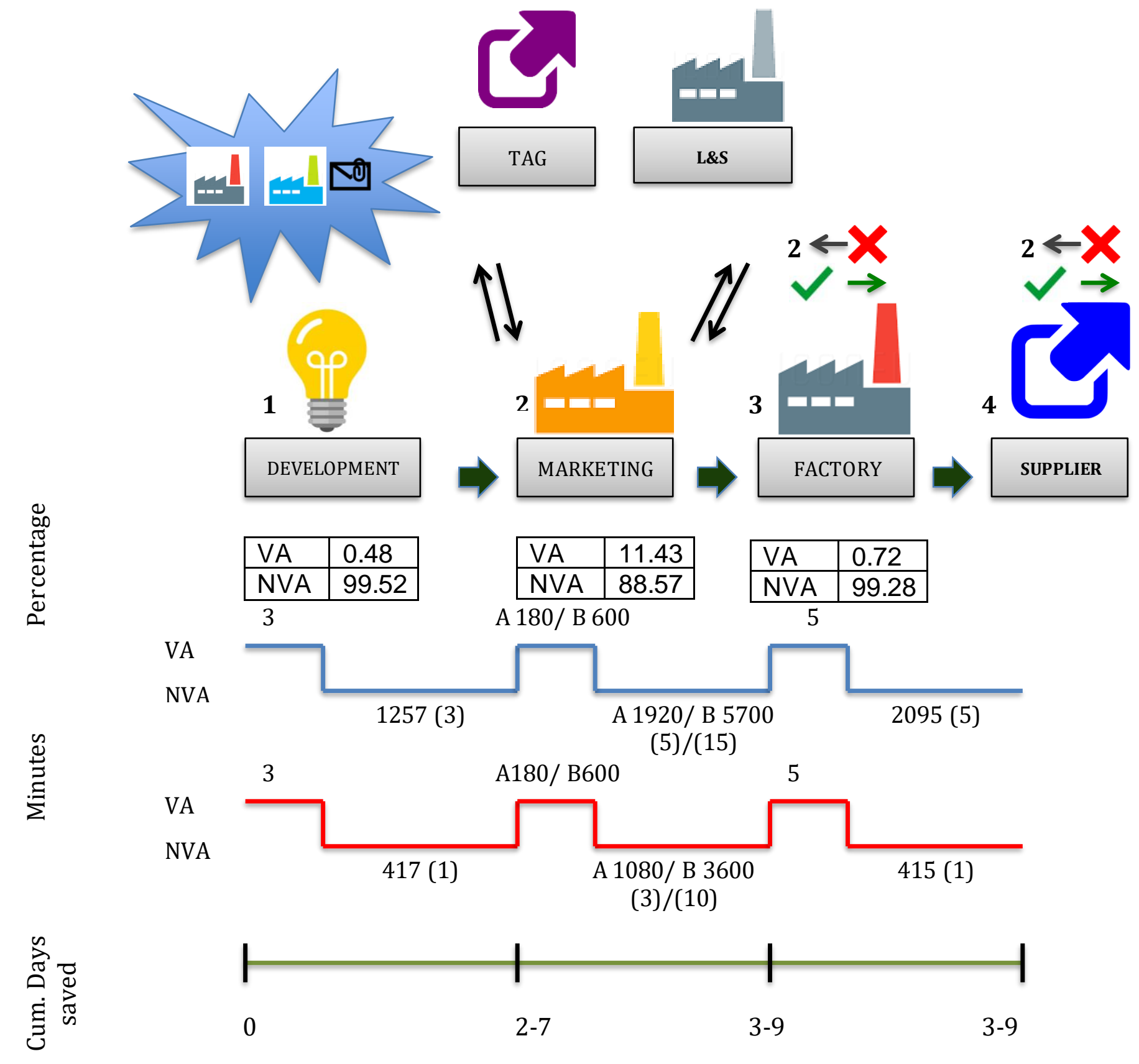




\section{TABLE 6: FINAL PROPOSED VSM}

\section{BAG APPROVAL}

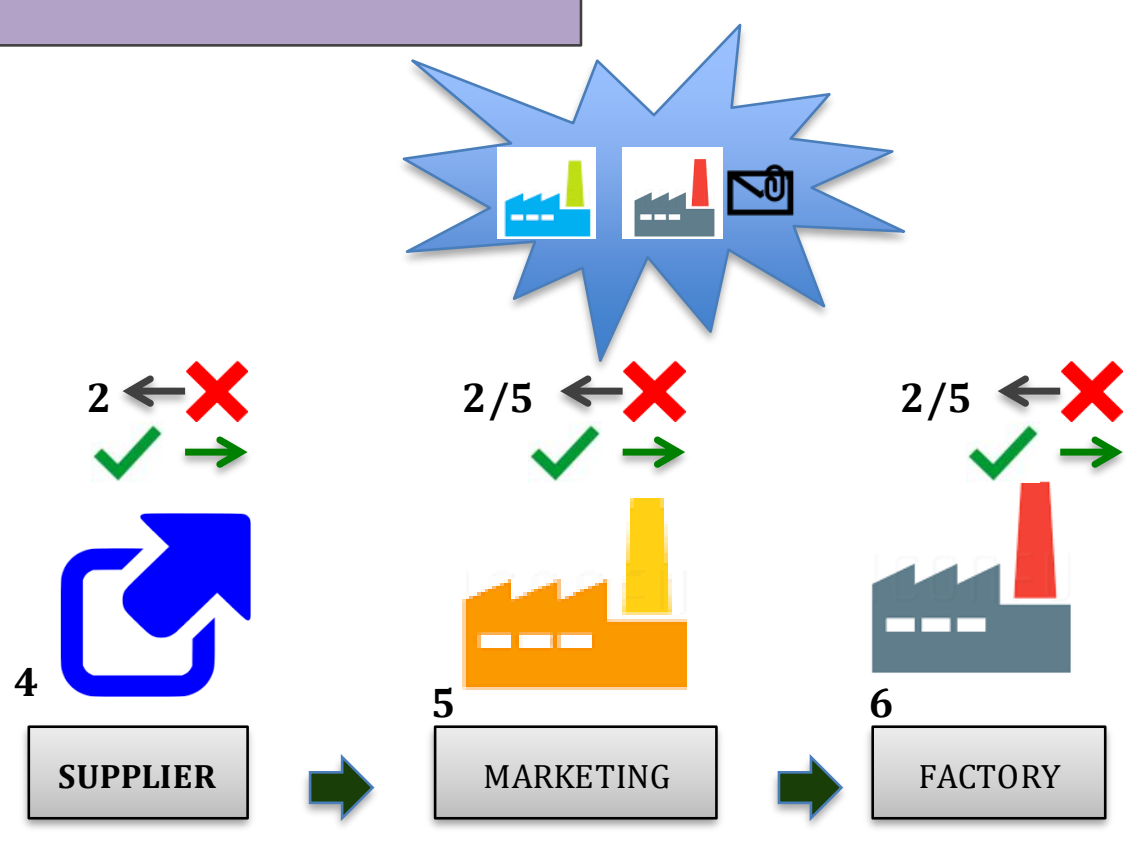

\begin{tabular}{|c|c|c|c|c|c|c|}
\hline ד & VA & 2.86 & VA & 8.61 & VA & 0.71 \\
\hline$\tilde{\tilde{d}}$ & NVA & 97.14 & NVA & 91.39 & NVA & 99.29 \\
\hline
\end{tabular}
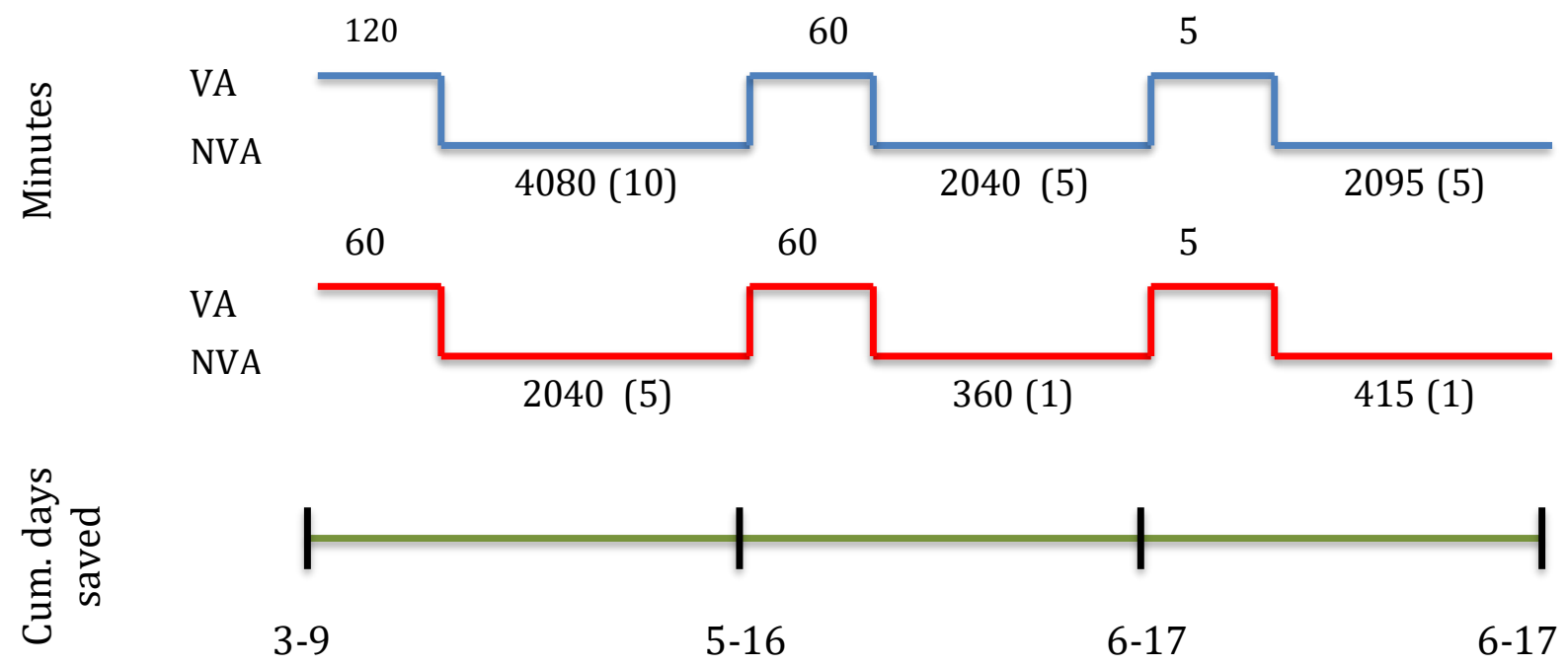